\title{
Erratum to: Effective session key distribution for secure fast handover in mobile networks
}

\author{
Jong Hyuk Park · Qun Jin
}

Published online: 3 December 2009

(C) Springer Science+Business Media, LLC 2009

Erratum to: Telecommun. Syst.

DOI 10.1007/s11235-009-9219-0

This article was published with an error in the affiliation of the first author. "Seoul National University" is incorrect. The correct name of the first author's institution is "Seoul National University of Technology" as shown in this erratum.

The online version of the original article can be found under doi:10.1007/s11235-009-9219-0.

J.H. Park ( $\varangle)$

Department of Computer Science and Engineering, Seoul

National University of Technology, Seoul, Korea

e-mail: parkjonghyuk1@ @otmail.com

Q. Jin

Department of Human Informatics and Cognitive Sciences,

Waseda University, Saitama, Japan

e-mail: jin@waseda.jp 